\title{
Dexmedetomidine combined with suprascapular nerve block and axillary nerve block has a synergistic effect on relieving postoperative pain after arthroscopic rotator cuff repair
}

\author{
Jae Jun Lee ${ }^{1}$ - Do-Young Kim² ${ }^{2}$ Jung-Taek Hwang ${ }^{2}$ (1) - Dong-Keun Song ${ }^{3} \cdot$ Han Na Lee ${ }^{1}$ Ji Su Jang ${ }^{1} \cdot$ Sang-Soo Lee $^{2}$. \\ Sung Mi Hwang ${ }^{1}$. Sung Hoon Moon ${ }^{4}$. Jae-Hoon Shim ${ }^{2}$
}

Received: 25 May 2020 / Accepted: 14 September 2020 / Published online: 25 September 2020

(c) European Society of Sports Traumatology, Knee Surgery, Arthroscopy (ESSKA) 2020

\begin{abstract}
Purpose Suprascapular nerve block (SSNB) is the most commonly used block for the relief of postoperative pain from arthroscopic rotator cuff repair and can be used in combination with axillary nerve block (ANB). Dexmedetomidine (DEX) is a type of alpha agonist that can elongate the duration of regional block. The aim of this study was to compare the effects of the use of dexmedetomidine combined with SSNB and ANB with those of the use of SSNB and ANB alone on postoperative pain, satisfaction, and pain-related cytokines within the first $48 \mathrm{~h}$ after arthroscopic rotator cuff repair.

Methods Forty patients with rotator cuff tears who had undergone arthroscopic rotator cuff repair were enrolled in this singlecenter, double-blinded randomized controlled trial study. Twenty patients were randomly allocated to group 1 and received ultrasound-guided SSNB and ANB using a mixture of $0.5 \mathrm{ml}(50 \mu \mathrm{g})$ of DEX and $9.5 \mathrm{ml}$ of $0.75 \%$ ropivacaine preemptively. The other 20 patients were allocated to group 2 and underwent ultrasound-guided SSNB and ANB alone using a mixture of $0.5 \mathrm{ml}$ of normal saline and $9.5 \mathrm{ml}$ of ropivacaine. The visual analog scale (VAS) for pain and patient satisfaction (SAT) scores were postoperatively checked within $48 \mathrm{~h}$. The plasma interleukin (IL)-6, IL-8, IL-1 $\beta$, cortisol, and serotonin levels were also postoperatively measured within $48 \mathrm{~h}$.

Results Group 1 showed a significantly lower mean VAS (visual analog scale of pain) score 1, 3, 6, 12, 18 and $24 \mathrm{~h}$ after operation, and a significantly higher mean SAT (patient satisfaction) score 1, 3, 6, 12, 18, 24 and $36 \mathrm{~h}$ after the operation than group 2. Group 1 showed a significantly lower mean plasma IL-8 level 1 and $48 \mathrm{~h}$ after the operation, and a significantly lower mean IL-1 $\beta$ level $48 \mathrm{~h}$ after the operation than group 2 . Group 1 showed a significantly lower mean plasma serotonin level $12 \mathrm{~h}$ after the operation than group 2. The mean timing of rebound pain in group 1 was significantly later than that in group $2(36 \mathrm{~h}>23 \mathrm{~h}, p=0.007)$. Six patients each in groups 1 and 2 showed rebound pain. The others did not show rebound pain. Conclusions Ultrasound-guided SSNA and ANB with DEX during arthroscopic rotator cuff repair resulted in a significantly lower mean VAS score and a significantly higher mean SAT score within $48 \mathrm{~h}$ after the operation than SSNB and ANB alone. Additionally, SSNB and ANB with DEX tended to result in a later mean timing of rebound pain accompanied by significant changes in IL-8, IL-1 $\beta$, and serotonin levels within $48 \mathrm{~h}$ after the operation. The present study could provide the basis for selecting objective parameters of postoperative pain in deciding the optimal use of medication for relieving pain.
\end{abstract}

Level of Evidence Level I.

Trial Registration 2015-20, ClinicalTrials.gov Identifier: NCT04398589.

IRB number 2015-20, Hallym University Chuncheon Sacred Heart Hospital.

Jae Jun Lee and Do-Young Kim authors are co-first authors, and equally contributed to this work.

Presentation: This study had been accepted as an oral presentation in 2020 AAOS, but it was canceled due to COVID 19.

Extended author information available on the last page of the article 
Keywords Suprascapular nerve block $\cdot$ Axillary nerve block $\cdot$ Postoperative pain $\cdot$ Arthroscopic rotator cuff repair $\cdot$ Painrelated cytokine $\cdot$ Rebound pain $\cdot$ Dexmedetomidine

\section{Introduction}

Shoulder arthroscopic surgery can be performed in inpatient or outpatient settings, but it may cause severe pain in the early postoperative period $[11,18,24]$. Therefore, it is important to regulate excessive postoperative pain by decreasing the pain to a tolerable level for the early return of patients to activities of daily living [18, 24].There are several regional blocks that can be used to relieve postoperative pain. Interscalene brachial plexus block (ISB) is one of the most powerful regional blocks for shoulder operations, but it has a relatively short duration of effect $[18,34]$. Suprascapular nerve block (SSNB) is the most commonly used method for controlling postoperative shoulder pain, and axillary nerve block (ANB) has recently been adopted as a type of regional block for shoulder pain control that is frequently used in combination with SSNB [9, 18, 24].

Dexmedetomidine (DEX), a selective agonist of $\alpha_{2^{-}}$ adrenergic receptors, can be an effective adjuvant to local anesthetics for peripheral nerve blocks [16]. Preclinical and clinical studies have described a prolonged duration of analgesia when DEX is added to bupivacaine, levobupivacaine, or ropivacaine regimens for peripheral perineural blocks [5, $6,14,18,27,30,37]$.

The alterations in pain-related cytokines after arthroscopic rotator cuff repair under SSNB and ANB combined with DEX have not been studied. Therefore, the present study was designed to test the hypothesis that DEX combined with ropivacaine for SSNB and ANB in elective shoulder operations would enhance the duration and effect of analgesia compared with ropivacaine alone and to assess the influence of DEX on serum interleukin (IL)-6, cortisol, IL-1 $\beta$, IL-8, and serotonin levels. The present study could provide the basis for selecting objective parameters of postoperative pain in deciding the optimal use of medication for relieving pain.

\section{Materials and methods}

All procedures were approved by the Institutional Review Board of Chuncheon Sacred Heart Hospital and were carried out in accordance with the Declaration of Helsinki (IRB number: 2015-20), and clinical trial registration was performed. The study inclusion criteria were as follows: (1) defined rotator cuff tear on preoperative MRI, indicating the need for repair; (2) willingness to undergo arthroscopic surgery, including rotator cuff repair; (3) age $>20$ years; and (4) willingness to undergo routine regional blocks and patient-controlled analgesia (PCA). The exclusion criteria involved patients who: (1) did not undergo arthroscopic rotator cuff repair; (2) stopped PCA before $48 \mathrm{~h}$ postoperatively due to side effects; (3) had a concomitant operation for a Bankart lesion; (4) had a history of shoulder operation or fracture; (5) had a concomitant neurological disorder involving the shoulder; (6) underwent conversion to open surgery from arthroscopy; (7) had contraindications for the routine regional blocks used in this study; or (8) had a known allergy or hypersensitivity against ropivacaine or dexmedetomidine, including other amino-amide local anesthetics or $\alpha_{2}$ adrenoceptor agonists.

Forty six patients with a rotator cuff tear who had undergone arthroscopic rotator cuff repair between May 2015 and December 2015 were enrolled in this study. All of the patients provided written informed consent to participate in the study. Rotator cuff tears were diagnosed by preoperative magnetic resonance imaging (MRI), and the size of the rotator cuff tear was confirmed at the time of surgery. The indication for surgery was a symptomatic full-thickness rotator cuff tear or a $>50 \%$ thickness partial-thickness rotator cuff tear in cases of failed conservative therapy [18].

Double-blinded randomization was performed as follows. The 46 patients who met the inclusion criteria were randomly assigned to 1 of 2 groups depending on the treatment. Randomization was performed with a computer random sequence generator by an independent nurse who prepared the syringes for the SSNB and ANB treatments according to the group assignment. The patients and all of the medical staff who participated in the surgery were blinded to the assignments. Two patients were excluded because they refused PCA just before the surgery. Four patients were excluded due to the omission of blood sampling or hemolysis of the blood sample. Thus, in total 40 patients were included. Among the patients, 20 were randomly allocated to group 1 and received SSNB and ANB with ropivacaine and DEX. The remaining 20 patients were allocated to group 2 and received SSNB and ANB with ropivacaine and normal saline (Fig. 1). The demographic data, such as the mean age, body mass index (BMI), and symptom duration, were similar between the two groups (Table 1).

\section{Data collection and outcome measures}

The visual analog scale (VAS) pain score; American Shoulder and Elbow Surgeons (ASES) Shoulder Score; Constant score; height; weight; and plasma cortisol, IL-6, IL-8, IL-1 $\beta$, and serotonin levels were checked preoperatively. ISB was 


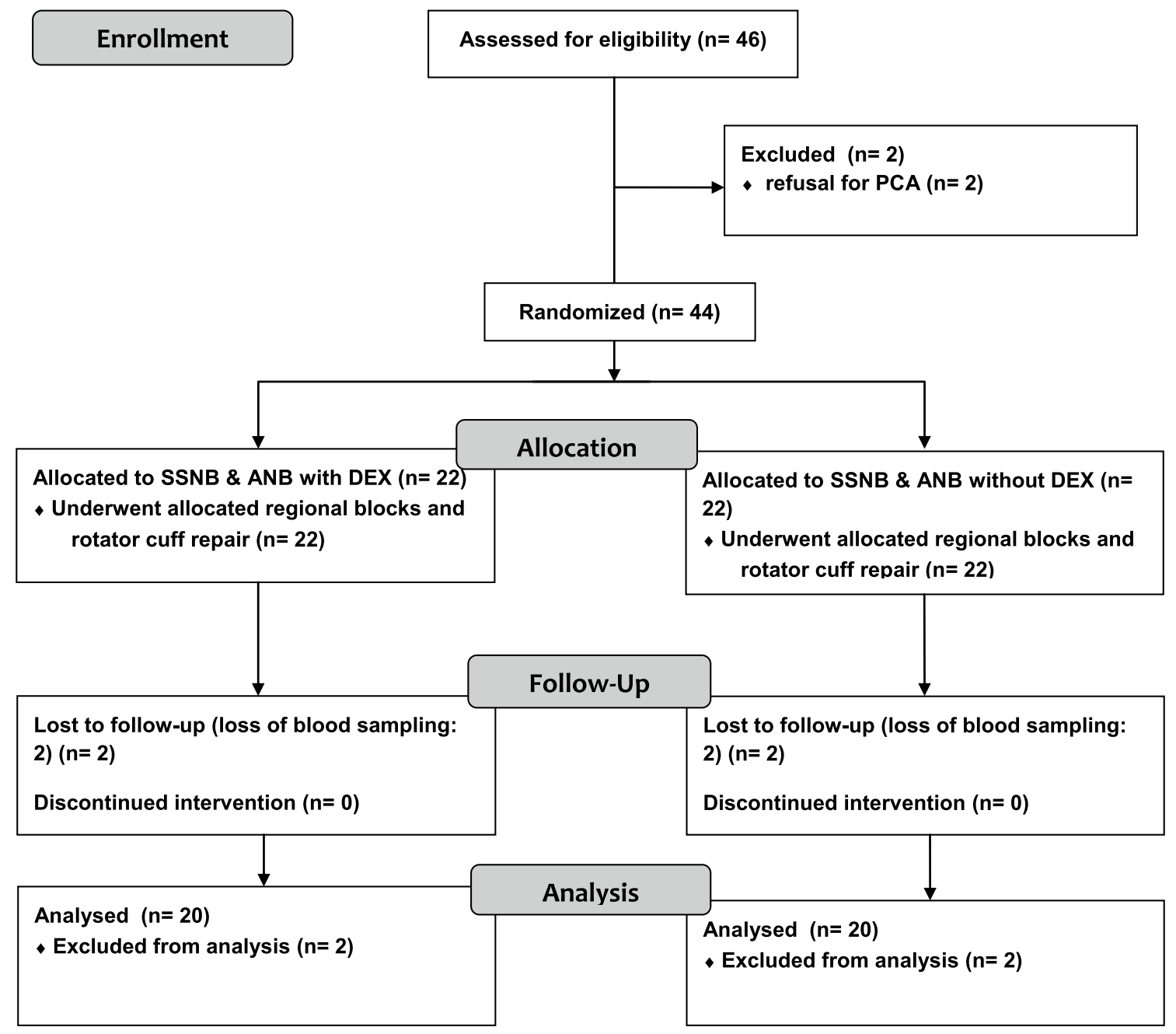

Fig. 1 Flow diagram. SSNB suprascapular nerve block, $A N B$ axillary nerve block, $D E X$ dexmedetomidine

performed preemptively under ultrasound guidance at the end of surgery. PCA was set at a fixed dose $(0.05 \mu \mathrm{g} / \mathrm{kg}$ loading dose and $0.03 \mu \mathrm{g} / \mathrm{min} / \mathrm{kg}$ continuous dose of fentanyl) to remove the effect of varying amounts of PCA [18, 24]. The VAS pain and patient satisfaction (SAT) scores were checked postoperatively at $1,3,6,12,18,24,36$, and $48 \mathrm{~h}$ by an independent orthopedic resident who was blinded to whether the patient received DEX during the surgery. The VAS pain score was based on a scale from 0.0 to 10.0 , where 0.0 indicated no pain and 10.0 indicated severe pain [18, 24]. The SAT score also ranged from 0.0 to 10.0 , where 0.0 indicated unsatisfactory and 10.0 indicated very satisfactory scores $[18,24]$. Plasma cortisol, IL-6, IL-8, IL-1 $\beta$, and serotonin levels were checked postoperatively at 1,6 , 12,24 , and $48 \mathrm{~h}$. Blood analysis was performed by laboratory staff who were blinded to the study assignments. A 3-ml blood sample was retrieved from the peripheral vein of the contralateral upper limb or both lower limbs per sampling, and 3.8\% sodium citrate (Sigma, St. Louis, Missouri,
USA) was immediately added to the collected blood as an anticoagulant. The blood was processed and stored at $4{ }^{\circ} \mathrm{C}$. Whole blood was centrifuged at $3000 \mathrm{rpm}$ for $10 \mathrm{~min}$. The plasma was separated from the blood cell layer and stored at $-40{ }^{\circ} \mathrm{C}$. The frozen plasma was thawed to $4{ }^{\circ} \mathrm{C}$ before the levels of blood markers were checked using several kits (Cortisol Parameter Assay Kit, Human IL-6 Quantikine ELISA Kit, Human CXCL8/IL-8 Quantikine ELISA Kit, Human IL-1 beta/IL-1F2 Quantikine ELISA Kit; R\&D systems, Minneapolis, Minnesota, USA, and Human Serotonin ELISA Kit; MyBioSource, San Diego, USA). The precision of the five blood markers was as follows: cortisol: intra-assay 5.4 9.2, interassay 9.3 21.2; IL-6: intra-assay $1.6 \sim 4.2$, interassay $3.3 \sim 6.4$; IL-8: intra-assay $5.4 \sim 6.5$; IL-1 $\beta$ : intra-assay 3.0 7.5, interassay $5.7 \sim 8.4$; and serotonin: intra-assay $9.7 \sim 12.6$, interassay $10.4 \sim 12.4$ [values are coefficients of variation (CVs; \%)] [23]. The primary outcome measure was the VAS score, and the secondary outcome measures were the SAT score and the levels of 
Table 1 Demographic data

\begin{tabular}{|c|c|c|c|c|}
\hline \multirow[t]{2}{*}{ Factors } & \multicolumn{3}{|l|}{ Value } & \multirow[t]{2}{*}{$p$-value } \\
\hline & Group I & Group I & Confidence interval of the difference & \\
\hline Number & 20 & 20 & & \\
\hline Age (years)* & $58.0 \pm 10.5(34-77)$ & $63.0 \pm 11.7(37-79)$ & $-12.1-2.2$ & n.s \\
\hline Gender (male:female) & $9: 11$ & $10: 10$ & $-0.4-0.3($ if male $=1$, female $=0)$ & n.s \\
\hline Dominant:nondominant & $15: 5$ & $12: 8$ & $\begin{array}{l}-0.2-0.5 \text { (if dominant }=1, \text { nondomi- } \\
\text { nant }=0)\end{array}$ & n.s \\
\hline Symptom duration (months)* & $10.9 \pm 15.2(0.03-66.0)$ & $14.4 \pm 18.5(0.1-54.0)$ & $-14.4-7.2$ & n.s \\
\hline Preoperative height $(\mathrm{cm})^{*}$ & $157.9 \pm 10.2(144.0-177.0)$ & $158.8 \pm 11.1(133.0-182.0)$ & $-7.6-5.9$ & n.s \\
\hline Preoperative weight $(\mathrm{kg})^{*}$ & $65.5 \pm 12.4(48.0-91.0)$ & $65.5 \pm 14.4(35.0-103.0)$ & $-8.7-8.6$ & n.s \\
\hline Preoperative BMI $\left(\mathrm{kg} / \mathrm{m}^{2}\right)^{*}$ & $26.1 \pm 3.1(21.5-33.0)$ & $25.8 \pm 3.9(19.2-32.5)$ & $-1.9-2.5$ & n.s \\
\hline Preoperative VAS* & $6.4 \pm 1.8(3.0-10.0)$ & $6.5 \pm 2.0(3.0-10.0)$ & $-1.3-1.2$ & n.s \\
\hline Preoperative ASES* & $40.6 \pm 17.9(3.3-70.0)$ & $40.2 \pm 18.6(10.0-75.0)$ & $-11.3-12.1$ & n.s \\
\hline Preoperative Constant* & $57.9 \pm 10.1(41.4-75.2)$ & $57.5 \pm 8.8(36.5-70.5)$ & $-5.6-6.4$ & n.s \\
\hline Preoperative Cortisol (ng/ml) & $33.6 \pm 19.1(9.3-88.6)$ & $39.3 \pm 28.2(6.4-93.8)$ & $-21.1-9.8$ & n.s \\
\hline Preoperative IL-6 (pg/ml) & $4.2 \pm 2.8(1.5-10.2)$ & $3.4 \pm 2.3(1.3-9.3)$ & $-0.8-2.5$ & n.s \\
\hline Preoperative IL-8 (pg/ml) & $8.5 \pm 4.7(3.6-25.5)$ & $8.2 \pm 3.1(3.4-18.6)$ & $-2.3-2.9$ & n.s \\
\hline Preoperative IL-1 $\beta(\mathrm{pg} / \mathrm{ml})$ & $2.3 \pm 0.4(1.4-3.0)$ & $2.1 \pm 0.3(1.6-2.7)$ & $-0.1-0.4$ & n.s \\
\hline Preoperative Serotonin (ng/ml) & $169.3 \pm 57.6(102.3-276.1)$ & $183.7 \pm 61.5(80.7-295.5)$ & $-52.6-23.7$ & n.s \\
\hline
\end{tabular}

The above analysis was performed using Mann-Whitney $U$ test or t-test for indifferent samples according to the normality of data to evaluate the differences between the mean values of the group I and group II. $P<.05$

$B M I$ body mass index, VAS visual analog scale pain score, ASES American shoulder and elbow surgeons score, Constant constant score, IL interleukin

*Factors are presented as the mean \pm standard deviation with the range in parentheses, Symptom duration: the duration between symptom onset and operation

plasma cortisol, IL-6, IL-8, IL-1 $\beta$, and serotonin. Postoperative rebound pain was confirmed if there was an increase in the VAS pain score between 1.0 and $48.0 \mathrm{~h}$ after the operation $[18,19]$.

\section{Interventions}

All regional blocks were performed preemptively. When the patient was set in the beach chair position, SSNB and ANB were performed by one anesthesiologist under ultrasound guidance (S-Nerve ${ }^{\mathrm{TM}}$, SonoSite, Bothell, WA, USA). SSNB was performed first, and the entry site was the midpoint between the anterolateral angle of the acromion and the medial end of the scapular spine. With the linear probe parallel to the scapular spine, the suprascapular notch was identified and the block was performed through the penetration of the transverse scapular ligament with a mixture of $9.5 \mathrm{ml}$ of $0.75 \%$ ropivacaine and $0.5 \mathrm{ml}(50 \mu \mathrm{g})$ of DEX or $0.5 \mathrm{ml}$ of normal saline because the scapular nerve and artery were located at the suprascapular notch [24]. ANB was performed just after SSNB, and the entry site was a point $1.5 \mathrm{~cm}$ medial and $2 \mathrm{~cm}$ inferior to the posterolateral angle of the acromion. With the linear probe parallel to the longitudinal axis of the humerus, the posterior circumflex artery was identified and the block was performed just above the artery with the same mixture as that of SSNB [24].

\section{Operative treatment}

All of the patients were hospitalized and underwent arthroscopic rotator cuff repair and subacromial decompression. All of the procedures were performed by one surgeon. Four routine arthroscopic portals (anterior, posterior, lateral, and posterolateral) were used during the surgery. Arthroscopic subacromial decompression was performed with acromioplasty, followed by the removal of spurs after bursectomy in all patients. The suture bridge technique was used for rotator cuff repair with 5.0-mm Bio-Corkscrew suture anchors (Arthrex, Naples, FL, USA) and a 4.75-mm BioSwiveLock device (Arthrex). Tendon-to-tendon sutures were occasionally used for small to medium tears located around the musculotendinous junction [18, 24]. Tenotomy or tenodesis of the long head of the biceps, distal clavicle resection, and anterior capsulectomy were performed simultaneously based on concomitant diseases. The indication for distal clavicle resection was symptomatic acromioclavicular arthritis, and the indication for anterior capsulectomy is adhesive capsulitis. Adhesive capsulitis was defined as 
passive forward elevation $<100^{\circ}$ and passive external rotation at the side $<30^{\circ}[18,31]$. The operation time was the duration between the first skin incision and suturing of the operative wound. There were no significant differences in the operative data between the two groups (Table 2).

\section{Postoperative rehabilitation}

A shoulder-immobilizing sling with an abduction pillow was prescribed to each patient postoperatively, with instructions to maintain the shoulder at $30-40^{\circ}$ internal rotation and $20^{\circ}$ abduction. Postoperative rehabilitation was individualized according to the size of the tear and the tissue quality of the torn rotator cuff. All of the patients were allowed passive forward elevation using a pulley $48 \mathrm{~h}$ after the operation, immediately after PCA had been removed $[18,32]$.

\section{Statistical analysis}

A total of 38 patients (19 patients in each group) would provide a statistical power of $80 \%$ with a two-sided $\alpha$ level of 0.05 to detect a significant difference in VAS $12 \mathrm{~h}$ after the operation, assuming an effect size of 0.97 [mean difference, 0.85 ; standard deviation (SD), 0.88]. This calculation was based on the mean and SD of the VAS observed in a pilot study of 20 patients measured $12 \mathrm{~h}$ after the operation. The normally distributed data between the groups were analyzed using independent-sample $t$ tests. Otherwise, the nonparametric Mann-Whitney $U$ test was used. Probable factors that may have affected rebound phenomenon characteristics were analyzed by univariate logistic regression. The statistical analysis was performed using IBM SPSS Statistics 22 (IBM Corp., Armonk, NY, USA). $p<0.05$ was considered statistically significant.

\section{Results}

Group 1 showed a significantly lower mean VAS (visual analog scale of pain) score $1,3,6,12,18$ and $24 \mathrm{~h}$ after the operation and a significantly higher mean SAT (patient satisfaction) at $1,3,6,12,18,24$ and $36 \mathrm{~h}$ after operation than group 2. (VAS: $3.9<5.3,3.5<4.4,3.1<4.0,2.8<3.7$, $2.6<3.2$ and $2.4<3.2(p=0.003, p=0.021, p=0.011$,

Table 2 Operative data

\begin{tabular}{|c|c|c|c|c|}
\hline \multirow[t]{2}{*}{ Factors } & \multicolumn{3}{|l|}{ Value } & \multirow[t]{2}{*}{$p$-value } \\
\hline & Group I & Group II & $\begin{array}{l}\text { Confidence interval of } \\
\text { the difference }\end{array}$ & \\
\hline Number & 20 & 20 & & \\
\hline Operation time (minute)* & $79 \pm 19(50-120)$ & $71 \pm 15(50-100)$ & $-3.0-18.5$ & n.s \\
\hline RCT size $(\mathrm{cm})^{*}$ & $2.6 \pm 1.6(1.0-6.0)$ & $2.3 \pm 1.4(0.7-5.0)$ & $-0.7-1.2$ & $\mathrm{n} . \mathrm{s}$ \\
\hline Suture bridge repair & 20 & 20 & & $\mathrm{n} . \mathrm{s}$ \\
\hline Single row repair & 0 & 0 & & n.s \\
\hline Tendon to Tendon repair & 0 & 0 & & $\mathrm{n} . \mathrm{s}$ \\
\hline \multicolumn{5}{|l|}{ SSC lesion } \\
\hline Debridement & 3 & 4 & $-0.3-0.2$ & n.s \\
\hline Repair using suture anchor & 2 & 1 & $-0.1-0.3$ & n.s \\
\hline Tendon to Tendon repair & 2 & 1 & $-0.1-0.2$ & n.s \\
\hline \multicolumn{5}{|l|}{ LHB lesion } \\
\hline Debridement & 3 & 5 & $-0.4-0.2$ & n.s \\
\hline Tenotomy & 1 & 0 & $-0.1-0.2$ & n.s \\
\hline Tenodesis & 5 & 4 & $-0.2-0.3$ & n.s \\
\hline ADCR & 1 & 0 & $-0.2-0.1$ & n.s \\
\hline Anterior capsulotomy & 2 & 1 & $-0.1-0.2$ & n.s \\
\hline Amount of fentanyl in PCA $(\mu \mathrm{g})$ & $5658 \pm 1068(4150-7867)$ & $5662 \pm 1248(3026-8904)$ & $-747.8-739.2$ & n.s \\
\hline
\end{tabular}

Anterior capsulotomy was performed for adhesive capsulitis. The above analysis was performed using Mann-Whitney $U$ test or $t$-test for indifferent samples according to the normality of data to evaluate the differences between the mean values of the group I and group II. $p<0.05$

$R C T$ rotator cuff tear, SSC subscapularis, $L H B$ long head of biceps, Debridement was performed for fraying or spontaneous rupture of LHB. Fraying was defined as a LHB lesion less than 50\%. Tenodesis or tenotomy was performed in cases with LHB dislocation, subluxation, or tear involving more than 50\%. ADCR arthroscopic distal clavicle resection, ADCR was performed for symptomatic AC arthritis, $A C$ acromioclavicular joint, $P C A$ patient-controlled analgesia

*Factors are presented as the mean \pm standard deviation with the range in parentheses. Operation time was the duration between the skin incision and suture 
$p=0.008, p=0.022$ and $p=0.018)$; SAT: $6.2>4.9,6.7>5.8$, $7.1>6.2,7.3>6.5,7.6>6.8,7.8>6.9$ and $7.9>7.4$ $(p=0.008, p=0.027, p=0.017, p=0.011, p=0.004$, $p=0.007$ and $p=0.037$ ), respectively) (Table 3). Group 1 showed a significantly lower mean plasma IL-8 level 1 and $48 \mathrm{~h}$ after the operation and a significantly lower mean IL- $1 \beta$ level $48 \mathrm{~h}$ after the operation than group 2 (IL-8: $7.8<11.1$ and $10.5<11.7$ ( $p=0.001$ and $p=0.006$ ); IL-1 $\beta$ : $3.6<4.1$ $(p=0.016)$, respectively). Additionally, group 1 showed a significantly lower mean plasma serotonin level $12 \mathrm{~h}$ after the operation than group $2[182.7<270.9(p=0.008)]$ (Table 4).

Six patients each in groups 1 and 2 showed rebound pain one time. The others did not show rebound pain. The mean timing of rebound pain in group 1 was significantly later than that in group $2(36.0 \mathrm{~h}>23.0 \mathrm{~h}, p=0.007)$, and the mean level of rebound pain in the two groups was not significantly different $(1.3<1.8, p=$ n.s.) (Table 5$)$. All of the cases of rebound pain occurred between 18 and $48 \mathrm{~h}$ after the operation.

\section{Discussion}

The most important finding of the present study was that ultrasound-guided SSNB and ANB with the addition of DEX tended to decrease the postoperative VAS and SAT scores after arthroscopic shoulder surgery compared to the scores with SSNB and ANB alone within the first $48 \mathrm{~h}$ after the operation. Pain is a major factor influencing the duration of hospital stay, and postoperative pain control is important for early rehabilitation and the early return of patients to activities of daily living [18, 24]. Several methods can be used for controlling postoperative pain after shoulder surgery. PCA can decrease some of the postoperative pain, but it may induce several side effects, such as nausea, vomiting, and somnolence [18, 39]. A continuous analgesic infusion pump is an effective method for relieving postoperative shoulder pain. However, leakage, occasional equipment malfunction, and infection can occur [4, 18, 28]. Several types of regional blocks, including ISB, SSNB, and ANB, can be used [9, 17-19, 24-26]. ISB is an efficacious method

Table 3 The scores associated with pain according to postoperative time

\begin{tabular}{|c|c|c|c|c|}
\hline \multirow[t]{2}{*}{ Postoperative time } & \multicolumn{3}{|l|}{ VAS score } & \multirow[t]{2}{*}{$p$-value } \\
\hline & Group I & Group II & $\begin{array}{l}\text { Confidence interval of the dif- } \\
\text { ference }\end{array}$ & \\
\hline \multicolumn{5}{|c|}{ VAS according to postoperative time ${ }^{\mathrm{a}}$} \\
\hline $1 \mathrm{~h}$ & $3.9 \pm 1.5(2.0-7.0)$ & $5.3 \pm 1.1(3.0-7.0)$ & $-1.6-(-0.2)$ & 0.003 \\
\hline $3 \mathrm{~h}$ & $3.5 \pm 1.2(2.0-6.0)$ & $4.4 \pm 1.2(3.0-7.0)$ & $-2.1-(-0.3)$ & 0.021 \\
\hline $6 \mathrm{~h}$ & $3.1 \pm 1.0(1.0-5.0)$ & $4.0 \pm 1.1(3.0-6.0)$ & $-4.2-(-1.5)$ & 0.011 \\
\hline $12 \mathrm{~h}$ & $2.8 \pm 0.8(1.0-4.0)$ & $3.7 \pm 0.9(3.0-6.0)$ & $-3.3-(-0.6)$ & 0.008 \\
\hline $18 \mathrm{~h}$ & $2.6 \pm 0.8(1.0-4.0)$ & $3.2 \pm 0.8(2.0-5.0)$ & $-1.9-(-0.1)$ & 0.022 \\
\hline $24 \mathrm{~h}$ & $2.4 \pm 0.8(1.0-4.0)$ & $3.2 \pm 1.1(2.0-5.0)$ & $-1.2-0.4$ & 0.018 \\
\hline $36 \mathrm{~h}$ & $2.4 \pm 1.0(1.0-5.0)$ & $2.7 \pm 0.9(1.0-4.0)$ & $-1.5-0.1$ & n.s \\
\hline $48 \mathrm{~h}$ & $1.8 \pm 0.9(0.0-4.0)$ & $2.1 \pm 0.7(1.0-3.0)$ & $-1.3-0.1$ & n.s \\
\hline \multirow[t]{2}{*}{ Postoperative time } & \multicolumn{3}{|l|}{ SAT } & \multirow[t]{2}{*}{$p$-value } \\
\hline & Group I & Group II & $\begin{array}{l}\text { Confidence interval of the dif- } \\
\text { ference }\end{array}$ & \\
\hline \multicolumn{5}{|c|}{ SAT according to postoperative time ${ }^{b}$} \\
\hline $1 \mathrm{~h}$ & $6.2 \pm 1.5(3.0-9.0)$ & $4.9 \pm 1.2(3.0-7.0)$ & $0.1-1.3$ & 0.008 \\
\hline $3 \mathrm{~h}$ & $6.7 \pm 1.2(4.0-9.0)$ & $5.8 \pm 1.3(3.0-8.0)$ & $0.1-1.6$ & 0.027 \\
\hline $6 \mathrm{~h}$ & $7.1 \pm 1.1(5.0-9.0)$ & $6.2 \pm 1.1(4.0-8.0)$ & $1.2-3.3$ & 0.017 \\
\hline $12 \mathrm{~h}$ & $7.3 \pm 0.8(6.0-9.0)$ & $6.5 \pm 1.1(4.0-9.0)$ & $0.6-2.4$ & 0.011 \\
\hline $18 \mathrm{~h}$ & $7.6 \pm 0.8(6.0-9.0)$ & $6.8 \pm 1.1(5.0-10.0)$ & $0.1-1.5$ & 0.004 \\
\hline $24 \mathrm{~h}$ & $7.8 \pm 0.9(6.0-9.0)$ & $6.9 \pm 1.1(4.0-8.0)$ & $0.0-1.2$ & 0.007 \\
\hline $36 \mathrm{~h}$ & $7.9 \pm 1.0(5.0-9.0)$ & $7.4 \pm 0.8(6.0-9.0)$ & $-0.3-0.7$ & n.s \\
\hline $48 \mathrm{~h}$ & $8.4 \pm 0.9(6.0-10.0)$ & $8.2 \pm 0.7(7.0-9.0)$ & $-0.1-0.7$ & n.s \\
\hline
\end{tabular}

${ }^{\mathrm{a}} V A S$ visual analog scale pain score. The above analysis was performed using Mann-Whitney $U$ test or $t$-test for indifferent samples according to the normality of data to evaluate the differences between the mean values of the group I and group II. $p<0.05$

${ }^{\mathrm{b}} S A T$ patient's satisfaction. The above analysis was performed using Mann-Whitney $U$ test or $t$-test for indifferent samples according to the normality of data to evaluate the differences between the mean values of the group I and group II. $p<0.05$ 
Table 4 The plasma level of pain-related cytokines according to postoperative time
Table 5 Characteristics of rebound pain according to the groups

\begin{tabular}{|c|c|c|c|}
\hline $\begin{array}{l}\text { Postopera- } \\
\text { tive time }\end{array}$ & Group I & Group II & $\begin{array}{l}\text { Confidence interval } \\
\text { of the difference }\end{array}$ \\
\hline
\end{tabular}

\begin{tabular}{lllll}
\hline \multicolumn{7}{l}{ (A) Cortisol (ng/ml) according to postoperative time ${ }^{\mathrm{a}}$} & & \\
$1 \mathrm{~h}$ & $138.1 \pm 46.4(20.6-191.4)$ & $165.6 \pm 35.4(116.0-230.5)$ & $-60.2-8.1$ & n.s \\
$6 \mathrm{~h}$ & $104.8 \pm 51.8(18.1-179.9)$ & $132.6 \pm 49.8(8.9-221.3)$ & -47.2 & n.s \\
$12 \mathrm{~h}$ & $66.4 \pm 28.3(23.8-131.7)$ & $81.5 \pm 51.6(22.7-188.8)$ & $-30.9-21.7$ & n.s \\
$24 \mathrm{~h}$ & $49.2 \pm 36.4(7.2-118.1)$ & $66.8 \pm 44.0(13.2-145.2)$ & $-22.2-12.2$ & n.s \\
$48 \mathrm{~h}$ & $24.9 \pm 18.4(5.1-78.7)$ & $39.1 \pm 23.8(8.3-80.5)$ & $-32.2-13.5$ & n.s
\end{tabular}

(B) IL-6 (pg/ml) according to postoperative time ${ }^{\mathrm{b}}$

$\begin{array}{lllll}1 \mathrm{~h} & 8.7 \pm 3.9(2.8-17.7) & 10.7 \pm 9.1(2.5-41.7) & -5.2 & \text { n.s } \\ 6 \mathrm{~h} & 14.7 \pm 5.1(3.9-26.2) & 22.2 \pm 14.0(9.2-64.5) & -13.1 & \text { n.s } \\ 12 \mathrm{~h} & 19.8 \pm 6.2(6.7-36.8) & 23.7 \pm 13.7(8.5-64.0) & -18.1 & \text { n.s } \\ 24 \mathrm{~h} & 21.7 \pm 6.0(11.9-35.1) & 32.3 \pm 17.2(11.6-69.6) & -17.1 & \text { n.s } \\ 48 \mathrm{~h} & 16.3 \pm 7.2(6.9-29.7) & 22.9 \pm 13.9(9.7-67.9) & -12.4-0.0 & \text { n.s }\end{array}$

(C) IL-8 (pg/ml) according to postoperative time ${ }^{\mathrm{b}}$

$\begin{array}{lllll}1 \mathrm{~h} & 7.8 \pm 2.1(4.0-13.9) & 11.1 \pm 3.8(6.2-20.8) & -3.0-0.1 & 0.001 \\ 6 \mathrm{~h} & 7.7 \pm 3.3(3.7-16.2) & 8.7 \pm 2.2(4.2-12.5) & -3 & 0.268 \\ 12 \mathrm{~h} & 8.1 \pm 2.6(2.9-13.7) & 9.1 \pm 2.9(4.2-16.6) & -2.9 & 0.257 \\ 24 \mathrm{~h} & 9.4 \pm 4.1(5.0-25.4) & 8.8 \pm 2.6(4.3-14.3) & -2.4 & 0.829 \\ 48 \mathrm{~h} & 10.5 \pm 4.5(6.7-27.7) & 11.7 \pm 2.3(8.2-16.6) & -2.9 & 0.006\end{array}$

(D) IL-1 $\beta(\mathrm{pg} / \mathrm{ml})$ according to postoperative time ${ }^{\mathrm{b}}$

$\begin{array}{lllll}1 \mathrm{~h} & 2.2 \pm 0.5(1.6-3.5) & 2.5 \pm 0.3(1.8-2.9) & -0.7-0.9 & \mathrm{n} . \mathrm{s} \\ 6 \mathrm{~h} & 2.4 \pm 0.5(1.7-3.7) & 2.7 \pm 1.2(1.4-7.4) & -0.3-1.5 & \mathrm{n} . \mathrm{s} \\ 12 \mathrm{~h} & 2.9 \pm 0.9(1.9-6.4) & 2.8 \pm 0.9(1.7-5.5) & -0.6-0.6 & \mathrm{n} . \mathrm{s} \\ 24 \mathrm{~h} & 2.7 \pm 0.4(1.9-3.3) & 3.0 \pm 0.8(2.2-5.3) & -0.5-1.0 & \mathrm{n} . \mathrm{s} \\ 48 \mathrm{~h} & 3.6 \pm 1.6(2.7-10) & 4.1 \pm 1.0(2.8-5.9) & -0.7-0.5 & 0.016\end{array}$

(E) Serotonin $(\mathrm{ng} / \mathrm{ml})$ according to postoperative time ${ }^{\mathrm{a}}$

\begin{tabular}{lllll}
$1 \mathrm{~h}$ & $192.7 \pm 83.3(64.5-340.5)$ & $225.0 \pm 86.8(91.4-376.8)$ & -28.4 & n.s \\
$6 \mathrm{~h}$ & $222.0 \pm 57.4(111.1-339.0)$ & $236.6 \pm 71.6(114.9-387.6)$ & $-18.6-13.1$ & n.s \\
$12 \mathrm{~h}$ & $182.7 \pm 93.1(23.1-372.7)$ & $270.9 \pm 105.8(102.0-468.4)$ & $-10.3-11.4$ & 0.008 \\
$24 \mathrm{~h}$ & $212.8 \pm 98.3(29.1-376.8)$ & $239.0 \pm 103.6(107.6-451.1)$ & $-4.5-20.4$ & n.s \\
$48 \mathrm{~h}$ & $174.7 \pm 74.8(45.8-289.1)$ & $184.5 \pm 90.2(71.5-386.9)$ & $-16.4-8.1$ & n.s \\
\hline
\end{tabular}

${ }^{\text {a }}$ The above analysis was performed using Mann-Whitney $U$ test or $t$-test for indifferent samples according to the normality of data to evaluate the differences between the mean values of the group I and group II. $p<0.05$

${ }^{\mathrm{b}} I L-6$ interleukin 6, $I L-8$ interleukin-8, $I L-1 \beta$ interleukin-1 $\beta$

\begin{tabular}{|c|c|c|c|c|}
\hline & Group I & Group II & $\begin{array}{l}\text { Confidence } \\
\text { interval of the } \\
\text { difference }\end{array}$ & $p$-value \\
\hline Rebound/No rebound & $6 / 14$ & $6 / 14$ & $\begin{array}{l}-0.3-0.3 \text { (if } \\
\text { rebound }=1, \\
\text { no } \\
\text { rebound }=0 \text { ) }\end{array}$ & n.s \\
\hline Mean size of rebound pain (VAS) & $1.3 \pm 0.5(1.0-2.0)$ & $1.8 \pm 0.4(1.0-2.0)$ & $-0.7-0.4$ & n.s \\
\hline Mean timing of rebound pain (h) & $36.0 \pm 7.6(24.0-48.0)$ & $23.0 \pm 2.4(18.0-24.0)$ & $-5.4-13.2$ & 0.007 \\
\hline
\end{tabular}

The above analysis was performed using Mann-Whitney $U$ test or $t$-test for indifferent samples according to the normality of data to evaluate the differences between the mean values of the group I and group II. $p<0.05$ 
but it may lead to pneumothorax or phrenic nerve palsy, and it has a shorter duration of effect than SSNB [18, 23, 26, 38]. SSNB is the most widely used method for pain control in arthroscopic shoulder surgery [24-26]. ANB is one of the recently adopted methods for shoulder pain control and it is frequently used in combination with SSNB to relieve lateral side pain in the shoulder [24, 26].

In this study, the combination of ultrasound-guided SSNB and ANB with DEX tended to decrease the postoperative VAS scores and increase the postoperative SAT scores after arthroscopic shoulder surgery compared to the scores with SSNB and ANB alone within the first $48 \mathrm{~h}$ after the operation. DEX combined with ropivacaine in SSNB and ANB increased the duration of the nerve block. The mechanism by which $\alpha_{2}$-adrenergic receptor agonists produce analgesia and sedation is not fully understood but is likely multifactorial. Peripherally, $\alpha_{2}$ agonists produce analgesia by reducing the release of norepinephrine and causing $\alpha_{2}$ receptor-independent inhibitory effects on nerve fiber action potentials. Centrally, $\alpha_{2}$ agonists produce analgesia and sedation by inhibiting the release of substance $\mathrm{P}$ in the nociceptive pathway at the level of the dorsal root neuron and by activating $\alpha_{2}$ adrenoceptors in the locus coeruleus [1, 7, 16, 18, 27]. Additionally, dexmedetomidine is associated with a decrease in serotonergic neurotransmission, which is correspondingly diminished by the stimulation of $5-\mathrm{HT}_{2}$ receptors $[22,33]$.

Pain-related blood markers include proinflammatory cytokines, anti-inflammatory cytokines, cortisol, and serotonin.[2, 3, 12, 13, 15, 18, 20, 33]. Cytokines influence the activity, differentiation, proliferation, and survival of immune cells, and they regulate the production and activity of other cytokines that can increase (proinflammatory) or decrease (anti-inflammatory) the inflammatory response. Proinflammatory cytokines include IL-1, IL-2, IL-6, IL-7, IL-8 and tumor necrosis factor (TNF), and anti-inflammatory cytokines include IL-4, IL-10, IL-13, and transforming growth factor (TGF) $\beta[8,9,10,12,18,21,29,35]$. It has also been reported that salivary and plasma cortisol levels are closely related to stress or pain $[10,18,20]$. Serotonin possibly induces peripheral antinociception through the release of endogenous opioid peptides [13]. Pain and the immune system influence each other, making it difficult to determine whether blocking nociception contributes to a reduction in the production of proinflammatory cytokines or vice-versa, with a reduction in the formation of proinflammatory cytokines resulting in less severe pain $[18,36]$.

The mean physiological blood levels are relatively lower than those in the present study because the operation caused pain. The mean plasma IL- 6 and IL- $1 \beta$ levels in patients who experience only narcosis are 2.04 and $38.53 \mathrm{pg} / \mathrm{ml}$, respectively $[18,40]$. According to these values, the mean blood level of IL- 6 is lower and the mean level of IL- $1 \beta$ is higher than the levels in the two groups from the present study.
Rebound pain has been reported in several studies in which regional blocks, such as ISB, SSNB, and ANB, were used to control pain after arthroscopic shoulder surgery $[11,16,18,19,26]$. One study showed that ANB combined with SSNB caused fewer rebound phenomena than SSNB alone [24]. Another study suggested that the combination of ISB and DEX tended to delay the mean timing of rebound pain compared to ISB alone [18]. In the present study, the mean time of rebound pain occurred later with ultrasound-guided SSNB and ANB combined with DEX than with ultrasound-guided SSNB and ANB alone, but the mean level of rebound pain was not significantly different between the two groups.

This study had a limitation. The VAS and SAT scores were subjective. However, all previous studies on preemptive regional blocks for postoperative pain control used these subjective scoring systems. DEX could be used in combination with SSNB and ANB for synergistic effects in relieving postoperative pain. The present study could provide the basis for selecting objective parameters of postoperative pain in deciding the optimal use of medication for relieving pain.

\section{Conclusions}

Ultrasound-guided SSNA and ANB with DEX in arthroscopic rotator cuff repair resulted in a significantly lower mean VAS score and a significantly higher mean SAT score within $48 \mathrm{~h}$ after the operation than SSNB and ANB alone. Additionally, SSNB and ANB with DEX tended to cause the mean timing of rebound pain occur later accompanied by significant changes in IL- 8 , IL- $1 \beta$, and serotonin levels within $48 \mathrm{~h}$ after operation.

Acknowledgements The authors thank Jun Sub Jung, a research agent for analyzing the blood samples.

Author contributions JJL: study design, performance of nerve blocks, data collection and analysis, interpretation of results. D-YK: study design, data collection and analysis, interpretation of results, preparation of tables, J-TH: study design, performance of operations, data collection and analysis, interpretation of results, manuscript writing. D-KS: study design, data collection and analysis, interpretation of results. HNL: study design, blood sampling, data collection and analysis, interpretation of results. JSJ: study design, interpretation of results, data collection and analysis. S-SL: study design, data collection and analysis, interpretation of results. S-MH: study design, data collection and analysis, interpretation of results. SHM: study design, data collection and analysis, interpretation of results, preparation of figure. J-HS: study design, data collection and analysis, interpretation of results.

Funding This work was supported by Hallym University Research Fund (HURF-2018-40; J.-T. H. and D.-Y. K.). 


\section{Compliance with ethical standards}

Conflict of interest The authors declare that they have no conflict of interest.

Ethical approval All procedures performed in studies involving human participants were in accordance with the ethical standards of the Institutional Review Board of Chuncheon Sacred Heart Hospital (IRB number: 2015-20) and with the 1964 Helsinki declaration and its later amendments or comparable ethical standards.

\section{References}

1. Abdallah FW, Brull R (2013) Facilitatory effects of perineural dexmedetomidine on neuraxial and peripheral nerve block: a systematic review and meta-analysis. Br J Anaesth 110(6):915-925

2. Beilin B, Bessler H, Mayburd E et al (2003) Effects of preemptive analgesia on pain and cytokine production in the postoperative period. Anesthesiology 98(1):151-155

3. Brenn D, Richter F, Schaible HG (2007) Sensitization of unmyelinated sensory fibers of the joint nerve to mechanical stimuli by interleukin-6 in the rat: an inflammatory mechanism of joint pain. Arthritis Rheum 56(1):351-359

4. Brown SL, Morrison AE (2004) Local anesthetic infusion pump systems adverse events reported to the Food and Drug Administration. Anesthesiology 100(5):1305-1307

5. Brummett CM, Hong EK, Janda AM, Amodeo FS, Lydic R (2011) Perineural dexmedetomidine added to ropivacaine for sciatic nerve block in rats prolongs the duration of analgesia by blocking the hyperpolarization-activated cation current. Anesthesiology 115(4):836-843

6. Brummett CM, Norat MA, Palmisano JM, Lydic R (2008) Perineural administration of dexmedetomidine in combination with bupivacaine enhances sensory and motor blockade in sciatic nerve block without inducing neurotoxicity in rat. Anesthesiology 109(3):502-511

7. Brummett CM, Williams BA (2011) Additives to local anesthetics for peripheral nerve blockade. Int Anesthesiol Clin 49(4):104-116

8. Cardozo LB, Cotes LC, Kahvegian MA et al (2014) Evaluation of the effects of methadone and tramadol on postoperative analgesia and serum interleukin-6 in dogs undergoing orthopaedic surgery. BMC Vet Res 10:194

9. Checcucci G, Allegra A, Bigazzi P, Gianesello L, Ceruso M, Gritti $G$ (2008) A new technique for regional anesthesia for arthroscopic shoulder surgery based on a suprascapular nerve block and an axillary nerve block: an evaluation of the first results. Arthroscopy 24(6):689-696

10. Choi JC, Lee JH, Choi E, Chung MI, Seo SM, Lim HK (2014) Effects of seasonal differences in testosterone and cortisol levels on pain responses under resting and anxiety conditions. Yonsei Med J 55(1):216-223

11. DeMarco JR, Componovo R, Barfield WR, Liles L, Nietert P (2011) Efficacy of augmenting a subacromial continuous-infusion pump with a preoperative interscalene block in outpatient arthroscopic shoulder surgery: a prospective, randomized, blinded, and placebo-controlled study. Arthroscopy 27(5):603-610

12. de Oliveira CM, Sakata RK, Issy AM, Gerola LR, Salomao R (2011) Cytokines and pain. Rev Bras Anestesiol 61(2):255-259 (60-5, 137-142)

13. Diniz DA, Petrocchi JA, Navarro LC et al (2018) Serotonin induces peripheral antinociception via the opioidergic system. Biomed Pharmacother 97:1434-1437
14. Esmaoglu A, Yegenoglu F, Akin A, Turk CY (2010) Dexmedetomidine added to levobupivacaine prolongs axillary brachial plexus block. Anesth Analg 111(6):1548-1551

15. Frank LA, Kunkle GA, Beale KM (1992) Comparison of serum cortisol concentration before and after intradermal testing in sedated and nonsedated dogs. J Am Vet Med Assoc 200(4):507-510

16. Fritsch G, Danninger T, Allerberger K et al (2014) Dexmedetomidine added to ropivacaine extends the duration of interscalene brachial plexus blocks for elective shoulder surgery when compared with ropivacaine alone: a single-center, prospective, triple-blind, randomized controlled trial. Reg Anesth Pain Med 39(1):37-47

17. Gautier P, Vandepitte C, Ramquet C, DeCoopman M, Xu D, Hadzic A (2011) The minimum effective anesthetic volume of $0.75 \%$ ropivacaine in ultrasound-guided interscalene brachial plexus block. Anesth Analg. 113(4):951-955

18. Hwang JT, Jang JS, Lee JJ et al (2020) Dexmedetomidine combined with interscalene brachial plexus block has a synergistic effect on relieving postoperative pain after arthroscopic rotator cuff repair. Knee Surg Sports Traumatol Arthrosc 28(7):23432353. https://doi.org/10.1007/s00167-019-05799-3. (Epub 2019 Nov 26)

19. Jeske HC, Krallinger F, Wambacher M et al (2011) A randomized study of the effectiveness of suprascapular nerve block in patient satisfaction and outcome after arthroscopic subacromial decompression. Arthroscopy 27(10):1323-1328

20. Karbic VO, Skoda M, Antoncic D, Kristofic I, Komar D, Trobonjaca Z (2014) Gabapentin-induced changes of plasma cortisol level and immune status in hysterectomized women. Int Immunopharmacol 23(2):530-536

21. Kosek E, Altawil R, Kadetoff D et al (2015) Evidence of different mediators of central inflammation in dysfunctional and inflammatory pain-interleukin- 8 in fibromyalgia and interleukin- 1 beta in rheumatoid arthritis. J Neuroimmunol 280:49-55

22. Koulu M, Pesonen U, Virtanen R (1990) Chronic dexmedetomidine, a selective alpha 2-agonist, decreases serotonin but not noradrenaline turnover in rat brainstem nuclei. Eur J Pharmacol 6(176):151-157

23. Lee JH, Cho SH, Kim SH et al (2011) Ropivacaine for ultrasound-guided interscalene block: $5 \mathrm{~mL}$ provides similar analgesia but less phrenic nerve paralysis than $10 \mathrm{~mL}$. Can J Anaesth 58(11):1001-1006

24. Lee JJ, Kim DY, Hwang JT et al (2014) Effect of ultrasonographically guided axillary nerve block combined with suprascapular nerve block in arthroscopic rotator cuff repair: a randomized controlled trial. Arthroscopy 30(8):906-914

25. Lee JJ, Yoo YS, Hwang JT et al (2015) Efficacy of direct arthroscopy-guided suprascapular nerve block after arthroscopic rotator cuff repair: a prospective randomized study. Knee Surg Sports Traumatol Arthrosc 23(2):562-566

26. Lee SM, Park SE, Nam YS et al (2012) Analgesic effectiveness of nerve block in shoulder arthroscopy: comparison between interscalene, suprascapular and axillary nerve blocks. Knee Surg Sports Traumatol Arthrosc 20(12):2573-2578

27. Marhofer D, Kettner SC, Marhofer P, Pils S, Weber M, Zeitlinger M (2013) Dexmedetomidine as an adjuvant to ropivacaine prolongs peripheral nerve block: a volunteer study. $\mathrm{Br} \mathrm{J}$ Anaesth 110(3):438-442

28. Matsen FA 3rd, Papadonikolakis A (2013) Published evidence demonstrating the causation of glenohumeral chondrolysis by postoperative infusion of local anesthetic via a pain pump. J Bone Joint Surg Am 95(12):1126-1134

29. Mendieta D et al (2016) IL-8 and IL-6 primarily mediate the inflammatory response in fibromyalgia patients. J Neuroimmunol 290:22-25 
30. Obayah GM, Refaie A, Aboushanab O, Ibraheem N, Abdelazees M (2010) Addition of dexmedetomidine to bupivacaine for greater palatine nerve block prolongs postoperative analgesia after cleft palate repair. Eur J Anaesthesiol 27(3):280-284

31. Oh JH, Oh CH, Choi JA, Kim SH, Kim JH, Yoon JP (2011) Comparison of glenohumeral and subacromial steroid injection in primary frozen shoulder: a prospective, randomized short-term comparison study. J Shoulder Elbow Surg 20(7):1034-1040

32. Park JY, Lhee SH, Oh KS, Kim NR, Hwang JT (2012) Is arthroscopic coracoplasty necessary in subcoracoid impingement syndrome? Arthroscopy 28(12):1766-1775

33. Rabin BC, Guo TZ, Gregg K, Maze M (1996) Role of serotonergic neurotransmission in the hypnotic response to dexmedetomidine, an alpha 2-adrenoceptor agonist. Eur J Pharmacol 306(1-3):51-59

34. Salviz EA, Xu D, Frulla A et al (2013) Continuous interscalene block in patients having outpatient rotator cuff repair surgery: a prospective randomized trial. Anesth Analg 117(6):1485-1492

35. Schaible HG, von Banchet GS, Boettger MK et al (2010) The role of proinflammatory cytokines in the generation and maintenance of joint pain. Ann N Y Acad Sci 1193:60-69

36. Shavit Y, Fridel K, Beilin B (2006) Postoperative pain management and proinflammatory cytokines: animal and human studies. J Neuroimmune Pharmacol 1(4):443-451
37. Swami SS, Keniya VM, Ladi SD, Rao R (2012) Comparison of dexmedetomidine and clonidine (alpha2 agonist drugs) as an adjuvant to local anaesthesia in supraclavicular brachial plexus block: a randomised double-blind prospective study. Indian J Anaesth 56(3):243-249

38. Thackeray EM et al (2013) Diaphragm function after interscalene brachial plexus block: a double-blind, randomized comparison of $0.25 \%$ and $0.125 \%$ bupivacaine. J Shoulder Elbow Surg 22(3):381-386

39. Watcha MF, White PF (1992) Postoperative nausea and vomiting. Its etiology, treatment, and prevention. Anesthesiology 77(1):162-184

40. Whitaker EE, Christofi FL, Quinn KM et al (2017) Selective induction of IL-1 $\beta$ after a brief isoflurane anesthetic in children undergoing MRI examination. J Anesth 31(2):219-224

Publisher's Note Springer Nature remains neutral with regard to jurisdictional claims in published maps and institutional affiliations.

\section{Affiliations}

\section{Jae Jun Lee ${ }^{1} \cdot$ Do-Young Kim ${ }^{2}$. Jung-Taek Hwang ${ }^{2}(1) \cdot$ Dong-Keun Song $^{3} \cdot$ Han Na Lee ${ }^{1} \cdot$ Ji Su Jang ${ }^{1} \cdot$ Sang-Soo Lee ${ }^{2}$. Sung Mi Hwang ${ }^{1}$. Sung Hoon Moon ${ }^{4}$ Jae-Hoon Shim ${ }^{2}$}

Jung-Taek Hwang

drakehjt@hanmail.net

1 Anesthesiology and Pain Medicine, Chuncheon Sacred Heart Hospital, Hallym University Medical College, Chuncheon-si, Republic of Korea

2 Department of Orthopedic Surgery, Chuncheon Sacred Heart Hospital, Hallym University Medical College, 77, Sakju-ro, Chuncheon-si, Gangwon-do 24253, Republic of Korea
3 Department of Pharmacology, Hallym University Medical College, Chuncheon-si, Republic of Korea

4 Department of Orthopedic Surgery, Kangwon National University Hospital, Kangwon National University Medical College, Chuncheon-si, Republic of Korea 